\title{
Measurements of the Flow in Backshroud/Casing Clearance of Precessing Centrifugal Impeller
}

\author{
YOSHIKI YOSHIDA ${ }^{\text {a }}$, YOSHINOBU TSUJIMOTO ${ }^{\mathrm{a}, *}$, HIDEO OHASHI $^{\mathrm{b}}$, AKIRA SAITO $^{\mathrm{a}}$ \\ and SHIN ISHIZAKI ${ }^{\mathrm{a}}$ \\ ${ }^{a}$ Engineering Science, Osaka University, Machikaneyama 1-3, Toyonaka, Osaka, 560 Japan; ${ }^{\mathrm{b}}$ Mechanical Engineering, \\ Kogakuin University, Nishishinjuku 1-24-2, Shinjuku, Tokyo, 163-91 Japan
}

(Received 6 March 1997; In final form 24 March 1997)

\begin{abstract}
Detailed flow measurements have been made to clarify the unsteady flow in the backshroud/ casing clearance of a precessing centrifugal impeller. The unsteady pressure was integrated to obtain the fluid force moment on the precessing impeller shroud for various precessing frequencies. It was shown that the fluid force moment can become rotordynamically destabilizing for small forward precessing motion as originally found by Ohashi et al. The effects of leakage flow in the backshroud/casing clearance and a gap between impeller side plate and casing at the impeller outlet are clearly shown, and the discussions are also made based on the unsteady velocity and pressure measurements.
\end{abstract}

Keywords: Precessing motion, Centrifugal pump, Rotordynamic moment, Unsteady flow, Leakage flow

\section{INTRODUCTION}

For high-performance turbomachines, rotordynamic stability is important for their acceptable and reliable operation. This is especially the case for high-speed pumps and compressors regarding self-exited vibration, which operate at a supercritical rotational speed. In order to analyze the rotordynamic stability at the development stage, it is necessary to know the rotordynamic fluid forces acting on each element of the rotor, such as journal bearing, wear ring, annular seal, moreover centri- fugal impeller itself. Rotordynamic forces occur in response to the shaft vibration, and may cause selfexited vibration of the rotor.

The motion of an impeller on a vibrating shaft can be divided into two fundamental modes. One is whirling motion, and the other is precessing motion. In the former studies for rotordynamic forces of centrifugal impellers in whirling motion, the following results have been obtained.

1. Rotordynamic fluid forces on a free impeller basically have no destabilizing effect except at

\footnotetext{
* Corresponding author.
} 
low flow rate (Ohashi et al. [1984] and Shoji et al. [1987]).

2. However, rotordynamic fluid forces on an impeller with a volute/guide vane have a destabilizing effect at a small whirling/rotating speed ratio due to the interaction between the impeller and the volute/guide vane (Chamieh et al. [1985], Bolleter et al. [1987] and Tsujimoto et al. [1988a]).

3. Moreover, rotordynamic fluid forces on an impeller shroud with a small shroud/casing clearance are destabilizing (Ohashi et al. [1988] and Adkin et al. [1988]). For the shroud forces of a whirling centrifugal impeller, numerical (Childs [1989] and Baskharone et al. [1994]) and experimental (Guinzburg et al. [1993]) investigations have been carried out to see the effect of leakage flow in the shroud/casing clearance and inlet swirl at the entrance of the clearance. It was found that the fluid forces on the shroud become more rotordynamically destabilizing with increasing the inlet swirl at the impeller outer radius.

On the other hand, fluid force mornents on a precessing impeller were measured by Ohashi et al. [1991] for the first time. It was found that rotordynamic moments on the impeller have a destabilizing effect at a small precessing/rotating speed ratio.

Present study is an extension of Ohashi's program for a precessing centrifugal impeller. The purposes of this study are as follows:

- To clarify the unsteady flow in the backshroud/ casing clearance of the centrifugal impeller in precessing motion.

- To investigate the effects of leakage flow in the backshroud/casing clearance, and the effect of a gap between the impeller side plate and casing, generally termed "Gap-A" (Guelich et al. [1989]), on fluid force moments acting on the backshroud.

Firstly, we describe the unsteady flow field, i.e., pressure and velocity distributions in the backshroud/casing clearance at various precessing/ rotating speed ratios. Secondly, we show the fluid force moments which were obtained by integration of the measured unsteady pressure, and also discuss the effects of the leakage flow and "Gap-A" on the rotordynamic shroud moment.

\section{EXPERIMENTAL APPARATUS}

The experimental apparatus in the present study is basically the same as Ohashi's original apparatus (Ohashi et al. [1991]). In order to examine the detailed flow in the backshroud/casing clearance, the casing and backshroud were modified to facilitate the measurements of unsteady pressure and velocity. For this aim, air is used as working fluid.

Figure 1 shows the mechanism to generate the precessing motion. The sleeve supports the pump shaft through two inner bearings, whose eccentricity can be adjusted to determine the shaft inclination. The pump shaft is connected to the driving shaft through the universal joint, and rotates with a constant speed $\omega(=677 \mathrm{rpm})$. The sleeve is driven by the controlled D.C. motor with a prescribed

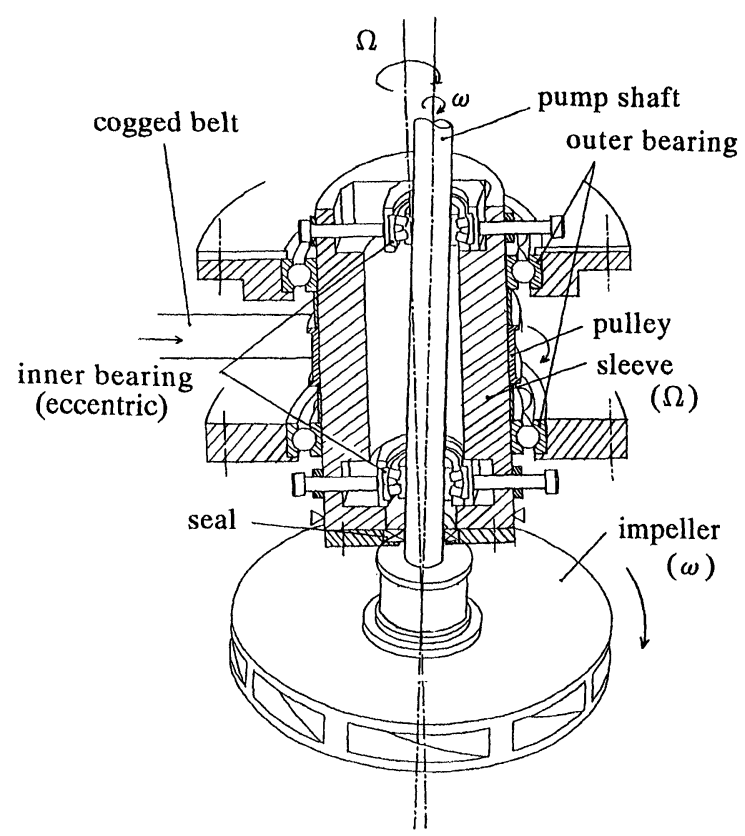

FIGURE 1 Explanation of the precessing generator. 
speed $\Omega$ through the cogged belt and pulley. The range of precessing/rotating speed ratio: $\Omega / \omega$ of $-1.4 \sim+1.4$ is covered in the present study. Prescribed precessing/rotating speed ratio is kept constant by a feedback circuit. Uncertainty in the precessing/rotating speed ratio is $\Omega / \omega= \pm 0.002$ during the measurement of unsteady flow. In this study, the center of precessing motion was placed at the impeller center "O" (see Fig. 2, center of the impeller outlet height) and the inclination of the shaft was set with $\alpha=0.9$ degree.

Figure 2 shows the details around the impeller. The test impeller is a model of a boiler feed pump and has a flat backshroud. The impeller has no guide-vanes and rotates in a symmetrical corrector in order to avoid the rotor-stator interaction. The mean backshroud/casing clearance is $\mathrm{Ho}=7.5 \mathrm{~mm}$. The gap between impeller side plate and casing at the impeller outlet (ordinary called "Gap-A"): S can be varied to be 1,2 , or $5 \mathrm{~mm}$ by changing the casing ring. In order to clarify the influence of the leakage flow, the inward leakage flow was adjusted by using a suction blower connected to "G" in Fig. 2 . $\mathrm{A} \sim \mathrm{F}$ in Fig. 2 show the locations of pressure and

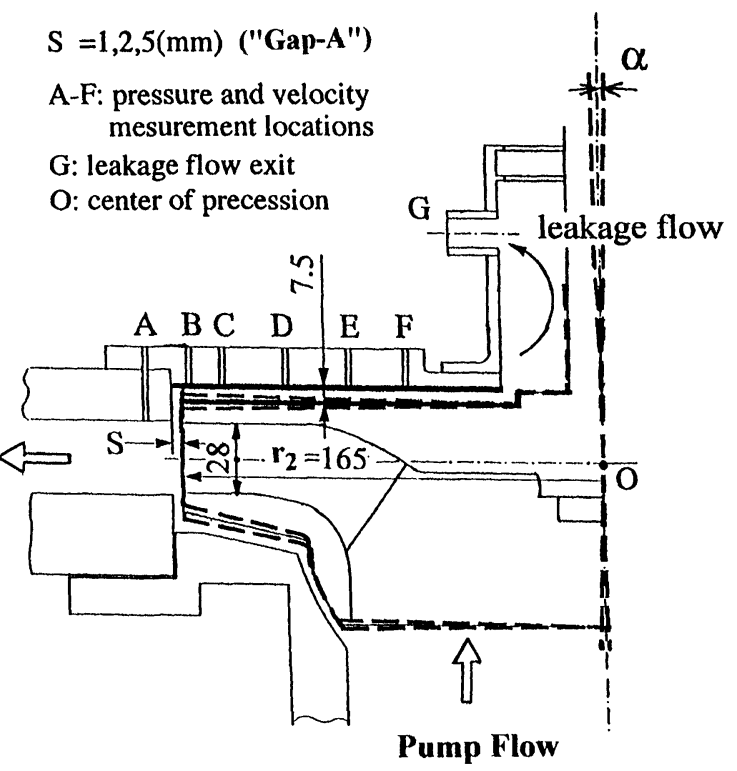

FIGURE 2 Experimental apparatus (Details around the impeller). velocity measurements. The pressure is measured on the casing wall by a semiconductor pressure transducer, and the velocity is measured by a hotwire anemometer at the depth $3 \mathrm{~mm}$ from the casing wall at each location. Uncertainty in the unsteady pressure is $\mathrm{p} / \rho\left(\mathrm{r}_{2} \omega\right)^{2}= \pm 0.001$ and in the unsteady velocity is $\mathrm{u} /\left(\mathrm{r}_{2} \omega\right)= \pm 0.01$. The pressure and velocity signals are ensemble averaged over 128 times with the precessing frequency. The phase relation between the measured signals and the precessing motion was determined by using an output of an eddy current displacement sensor measuring the backshroud/casing clearance at a circumferential location. The unsteady pressure and velocity thus measured on the stationary coordinate were used to determine the steady pattern of pressure and velocity distributions rotating with the precessing frequency, as shown in Fig. 8.

The fluid force moments on the backshroud are estimated from an integration of the measured pressure distribution between the radii $\mathrm{r}=47.5 \mathrm{~mm}$ and $\mathrm{r}=165 \mathrm{~mm}$. The calculated fluid force moment is divided into two components: radial $\left(M_{r}\right)$ and tangential $\left(\mathrm{M}_{\mathrm{t}}\right)$ components. Fig. 3 shows a coordinate system $(\mathrm{r}, \mathrm{t})$ on the backshroud rotating with the precessing frequency. The $\mathrm{r}$-axis is located at the maximum backshroud/casing clearance and the tangential axis (t-axis) is placed perpendicular to it. The components of the moment $\mathrm{M}_{\mathrm{r}}, \mathrm{M}_{\mathrm{t}}$ are defined as shown in the figure. Fluid moments are normalized using $\mathbf{M}_{\mathrm{o}}=\mathrm{I} \alpha \omega^{2}$, (where, $\mathrm{I}=\rho \pi \mathrm{r}_{2}^{2} \mathrm{~b}_{2} \mathrm{i}^{2}, \mathrm{i}=$ $\sqrt{r_{2}^{2} / 4+b_{2}^{2} / 12}$ and the normalized values are denoted by $M_{r}, M_{t}$ in the following sections. Uncertainty in the normalized moment is $\mathrm{M}_{\mathrm{r}}, \mathrm{M}_{\mathrm{t}}= \pm 2$.

We should note here that the fluid force moment is rotordynamically destabilizing for the precessing motion in case of $\mathrm{M}_{\mathrm{r}} \times(\Omega / \omega)>0$.

\section{EXPERIMENTAL RESULTS}

\section{Steady Flow}

Figure 4 shows the static pressure performance of the test pump. The design flow coefficient 

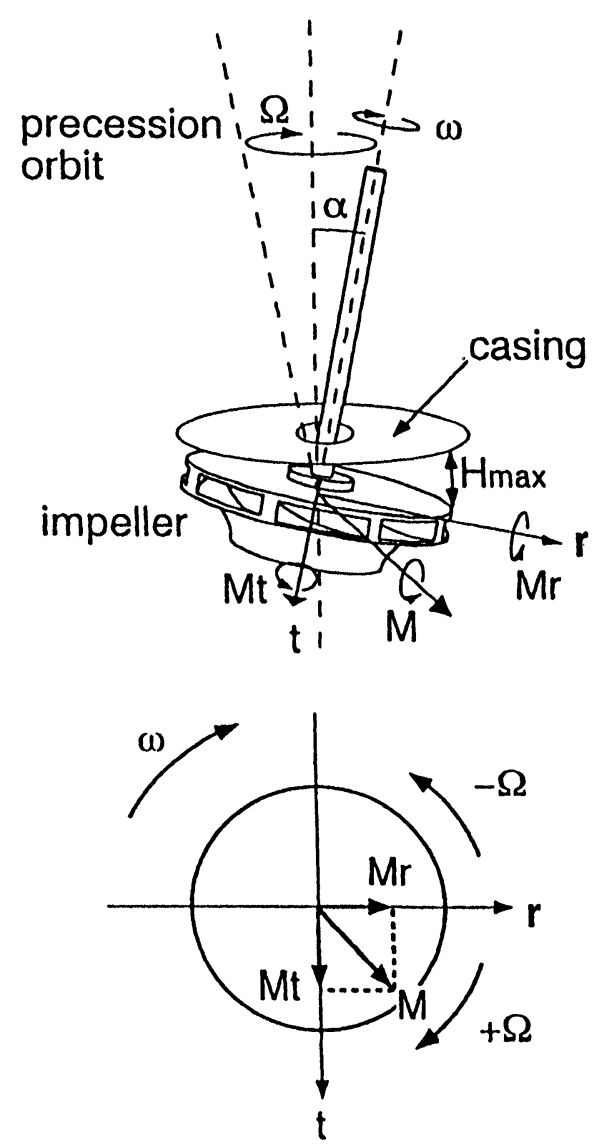

FIGURE 3 Coordinate system and components of moment.

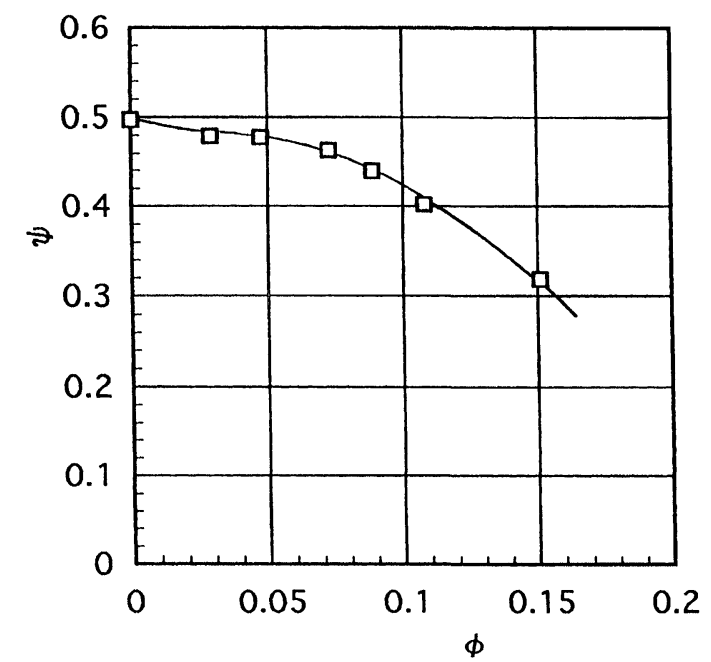

FIGURE 4 Static pressure performance of test pump $\left(\phi_{1}=\right.$ $0.0, \mathrm{~S}=2 \mathrm{~mm}$ ).

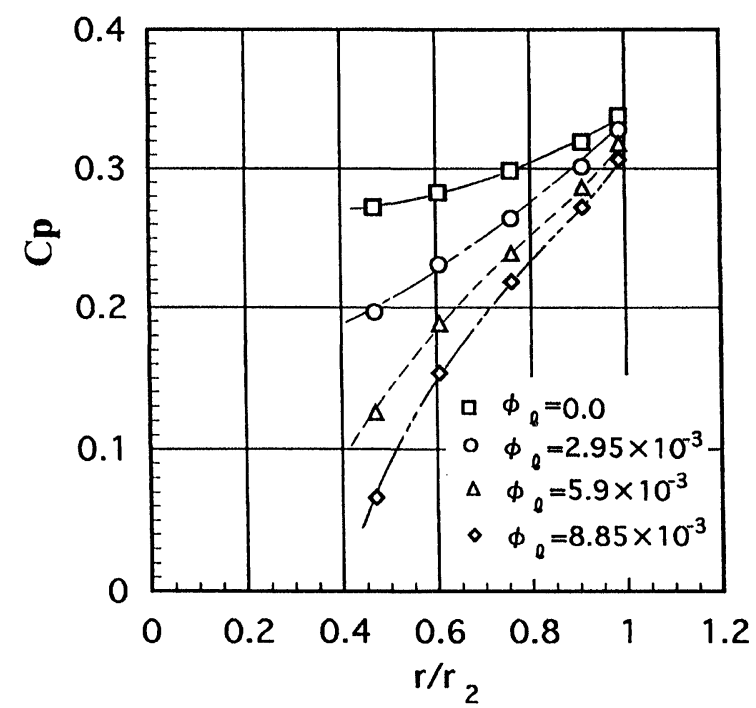

FIGURE 5 Pressure distributions on the backshroud $(\phi=$ $0.106, \mathrm{~S}=2 \mathrm{~mm}$ ).

is $\phi_{\mathrm{d}}=0.106$, and $\phi-\psi$ curve has negative slope in whole flow range. Figure 5 shows the radial pressure distribution measured at the locations $\mathrm{B} \sim \mathrm{F}$ (in Fig. 2) at $\phi=0.106$, under normal conditions without tilting. The pressure in the backshroud/casing clearance decreases with increasing the leakage flow ( $\phi_{1}$ : leakage flow coefficient). The inward leakage flow has a circumferential component due to the flow at the impeller outlet, which brings some additional circumferential momentum into the flow in the backshroud/casing clearance. Consequently, the rotation of the flow in the clearance increases with increasing the leakage flow. The circumferential velocity component $\mathrm{U}_{\theta}$ was estimated from the pressure distribution in Fig. 5. It is assumed that the pressure gradient is balanced by the centrifugal force: $\mathrm{dp} / \mathrm{dr}=\rho \mathrm{U}_{\theta}^{2} / \mathrm{r}$. Figure 6 shows the estimated circumferential velocity distribution. The swirl increases in the clearance, especially at the inner area, with increasing the inward leakage flow.

\section{Unsteady Flow}

Figure 7 shows the velocity distribution in the backshroud/casing clearance at the location $\mathrm{E}$ 


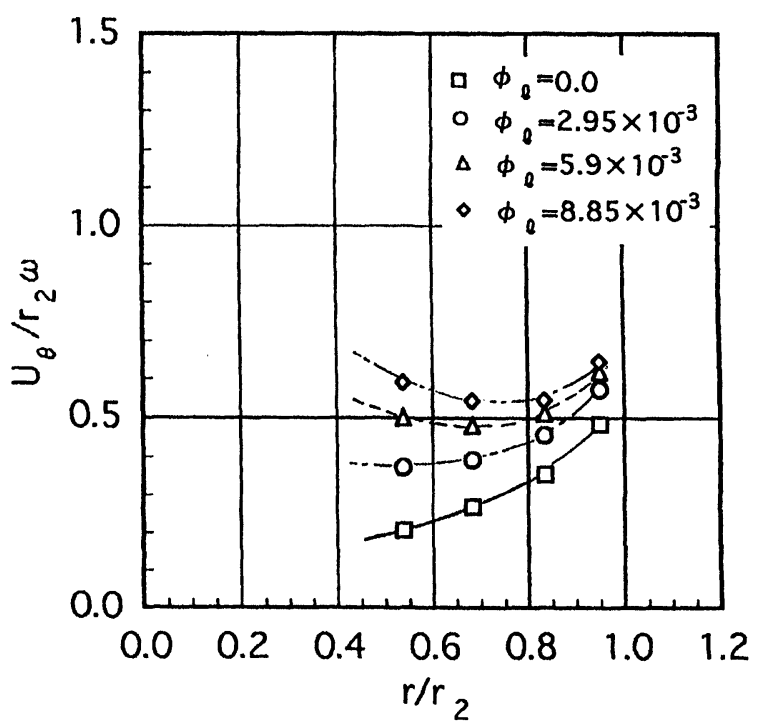

FIGURE 6 Circumferential velocity distribution on the backshroud (estimated from Fig. 5).

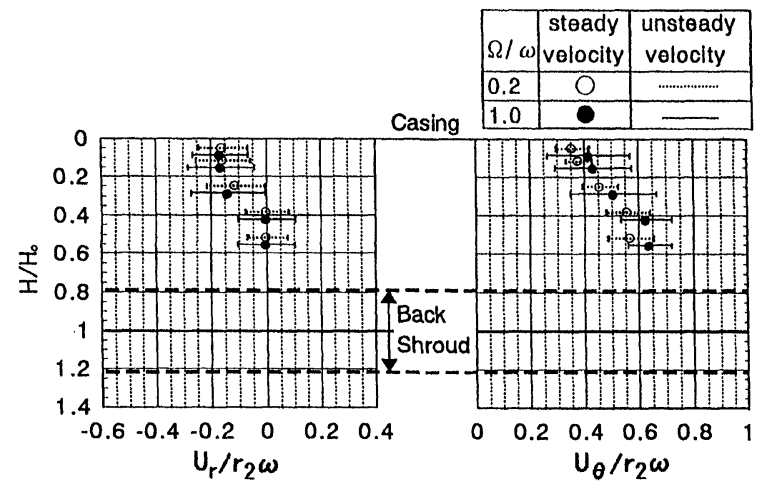

FIGURE 7 Velocity profiles in the backshroud/casing clearance $\left(\phi=0.106, \phi_{1}=0.0, \mathrm{~S}=2 \mathrm{~mm}\right)$.

$(\mathrm{r}=100 \mathrm{~mm})$, with the precessing motion and no leakage flow. In this location, the backshroud/ casing clearance fluctuates within $\mathrm{H}=5.9 \mathrm{~mm} \sim$ $9.1 \mathrm{~mm}$. It is found that the steady velocity of radial component has an inward flow $(\mathrm{Ur}<0)$ near the casing. However, Ur equals 0 at the center of the clearance. The averaged circumferential component is almost $\mathrm{U}_{\theta} / \mathrm{r} \omega \approx 0.5$. On the other hand, the amplitudes of the unsteady components are almost constant over the depth. Although not shown in this figure, the phase between the velocity fluctuation and the precessing motion didn't change over the depth. Therefore unsteady velocity was measured at the depth $3 \mathrm{~mm}\left(\mathrm{H} / \mathrm{H}_{\mathrm{o}}=0.4\right)$ from the casing wall hereafter.

Figure 8 shows the unsteady pressure and velocity distributions on the backshroud which would be seen in the frame rotating with the precessing frequency. It can be found that the pressure and velocity fields depend on the precessing/rotating speed ratio. The circumferential location of the pressure distribution doesn't change in $|\Omega / \omega|>0.6$; however, it rotates rapidly in $\mid \Omega /$ $\omega \mid<0.6$. The amplitude of the pressure increases with increasing of $|\Omega / \omega|$. The maximum (minimum) pressure occurs just before the radial velocity at the impeller outlet attains its maximum (minimum). Fluid force moments on the backshroud in the following paragraph were obtained by integrating the pressure distributions as shown in Fig. 8.

\section{Fluid Moments}

Firstly, the effect of pump flow rate was investigated. Figure 9 shows the normalized moment components at various pump flow rates: $\phi=0.029$, $0.070,0.106$, without leakage flow. Radial component $M_{r}$ is positive at a small precessing/rotating speed ratio: $0<\Omega / \omega<0.5$, which indicates the destabilizing effect for the precessing motion. This result and other general characteristics of $M_{r}$ and $\mathbf{M}_{\mathbf{t}}$ are same as the direct total moment measurements by Ohashi et al. [1991]. This coincidence shows that the fluid force moment on the backshroud plays an important role in the total fluid force moment on a precessing centrifugal impeller. From the figure, it is found that the fluid force moments are almost independent of the pump flow rate. This character is different from that of the fluid forces on the whirling impeller with a volute/ guide vane, which become more destabilizing at lower flow rate (Chamieh et al. [1985] and Tsujimoto et al. [1988a]).

Secondly, the effect of the leakage flow rate was investigated. Figure 10 shows the fluid moment at various leakage flow rates: $\phi_{1}=0.0,2.95,5.9$, 


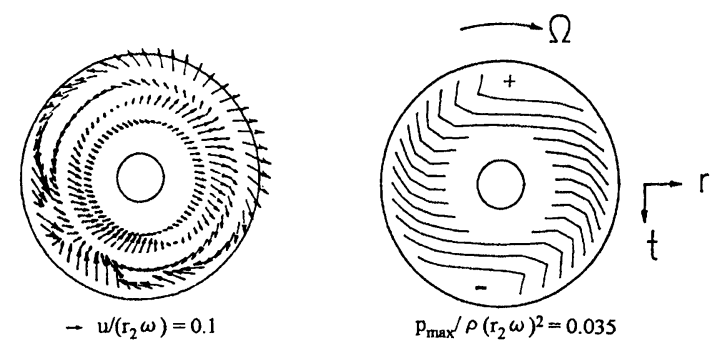

(a) $\Omega / \omega=1.0$
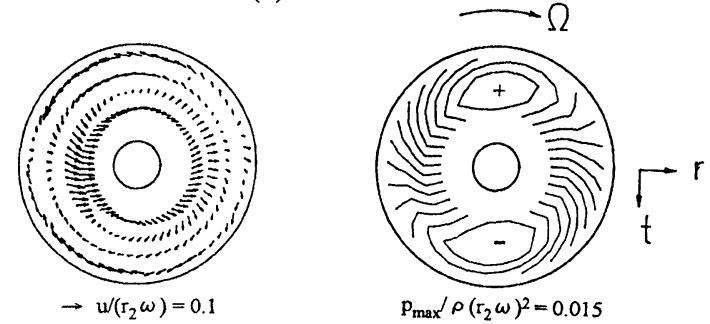

(b) $\Omega / \omega=0.6$

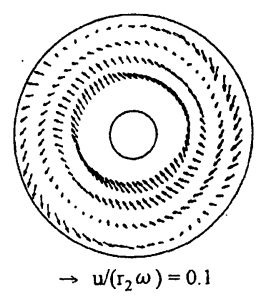

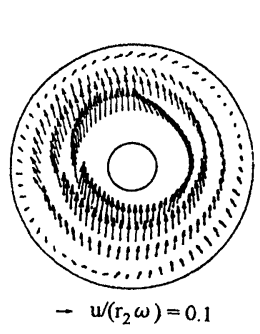

(d) $\Omega / \omega=-0.2$

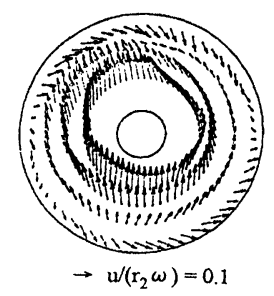

(e) $\Omega / \omega=-0.6$
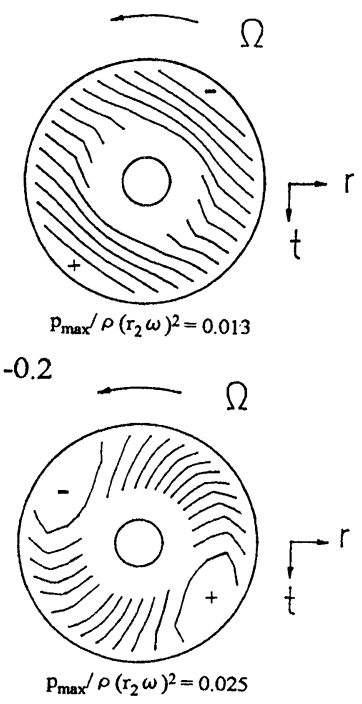

(c) $\Omega / \omega=0.2$

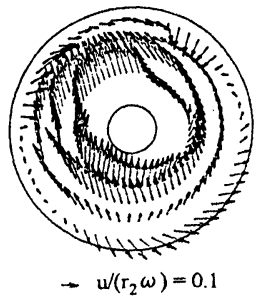

(f) $\Omega / \omega=-1.0$

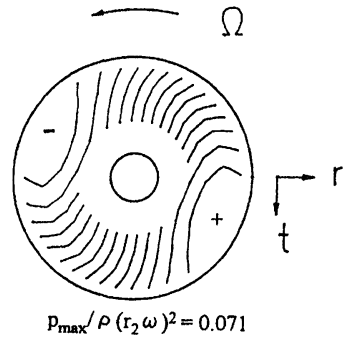

FIGURE 8 Velocity and pressure distributions on the backshroud $\left(\phi=0.106, \phi_{1}=0.0, \mathrm{~S}=2 \mathrm{~mm}\right)$.
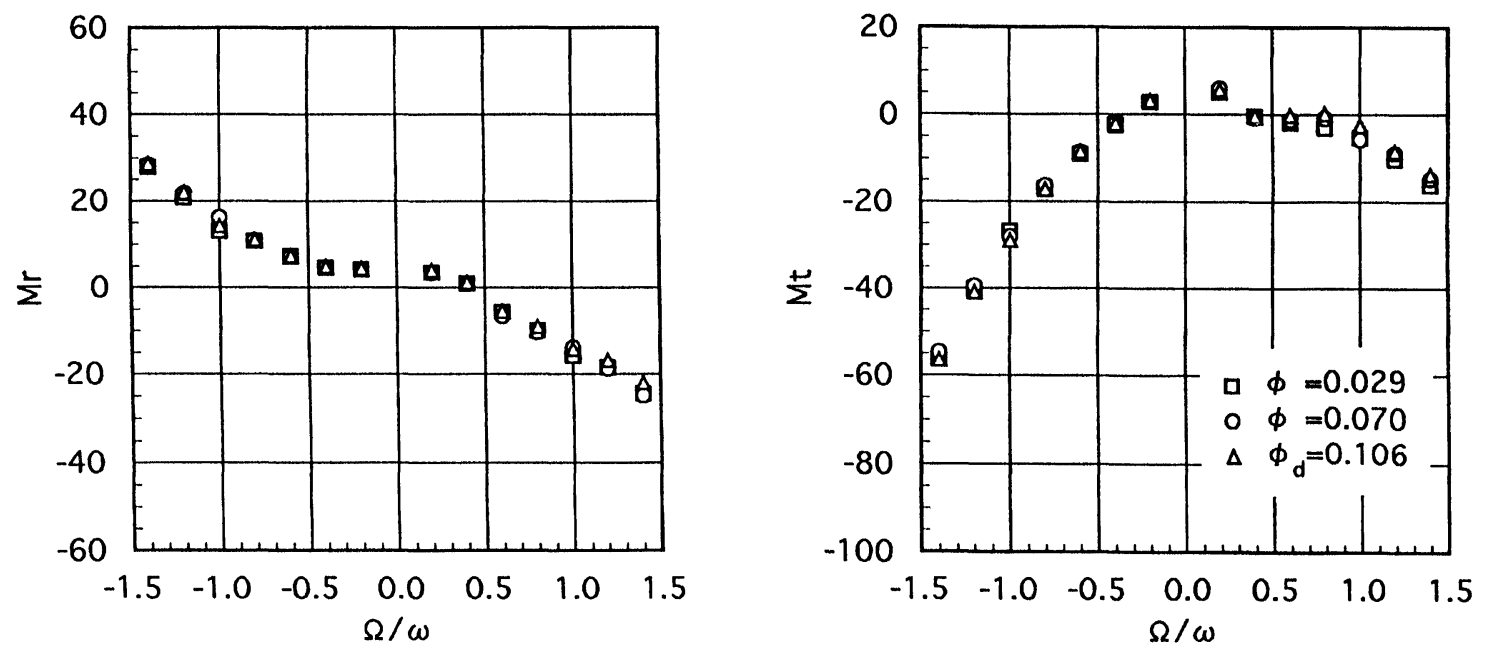

FIGURE 9 Normalized moment components (influence of pump flow rate; $\phi_{1}=0.0, \mathrm{~S}=2 \mathrm{~mm}$ ). 

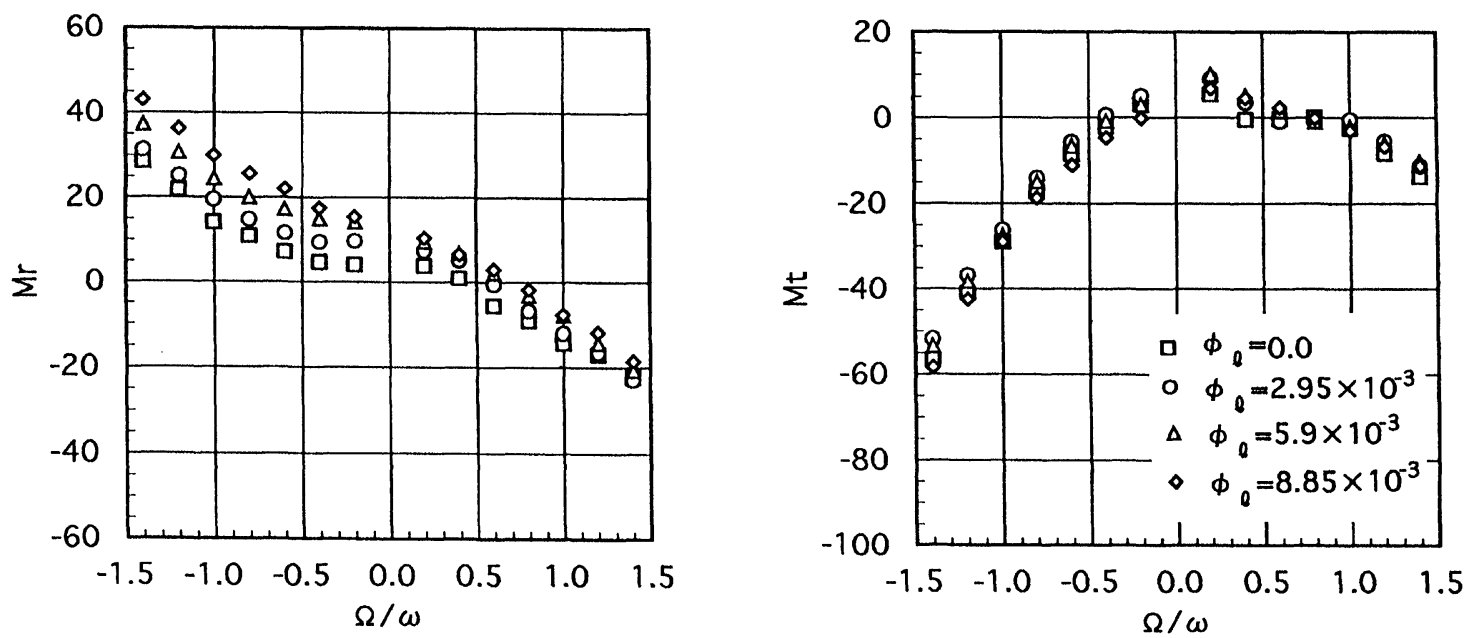

FIGURE 10 Normalized moment components (influence of leakage flow; $\phi=0.106, \mathrm{~S}=2 \mathrm{~mm}$ ).
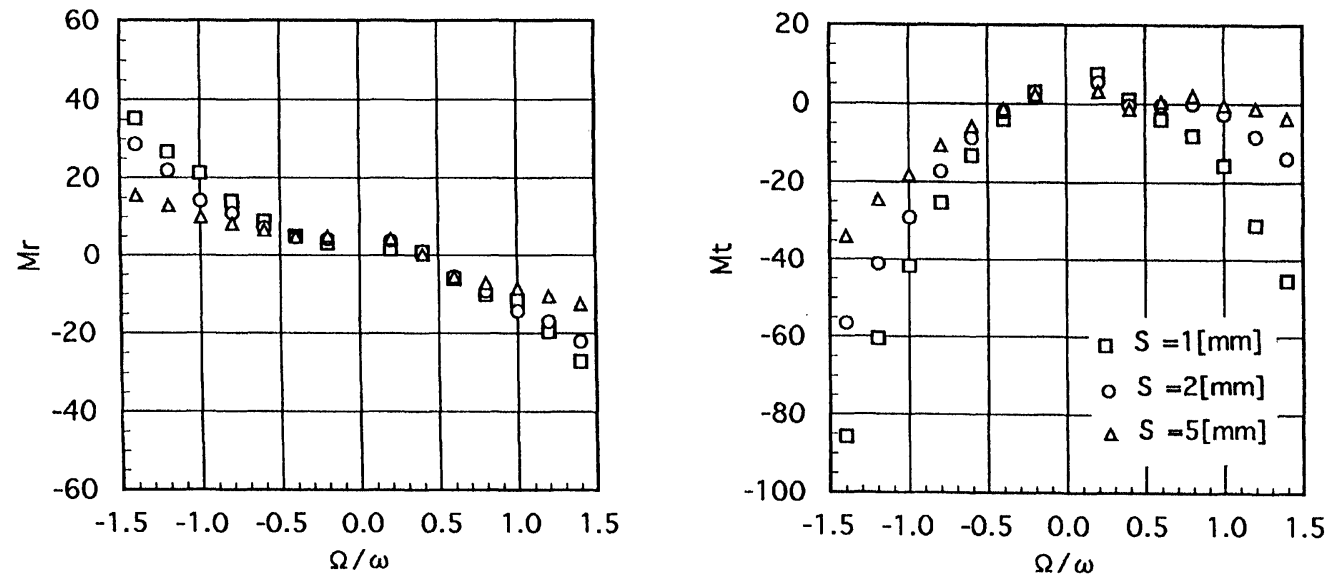

FIGURE 11 Normalized moment components (influence of the gap; $\phi=0.106, \phi_{1}=0.0$ ).

$8.85 \times 10^{-3}$. The leakage flow rate $\phi_{1}=2.95 \times 10^{-3}$ equals $2.8 \%$ of the design flow rate $\phi_{\mathrm{d}}=0.106$. With increasing the leakage flow, the curve of $M_{r}$ shifts to the right, and the fluid force moment becomes more destabilizing. However, $M_{t}$ is almost independent of the leakage flow. It was found from the measurements of steady flow that swirl in the backshroud/casing clearance increases with increasing the leakage flow, as shown in Fig. 6. It is noteworthy that the effect of the leakage flow on the fluid force moment on the precessing back- shroud is the same as that of the inlet swirl on the fluid force on the whirling shroud (Childs [1989] and Guinzburg et al. [1993]).

Thirdly, the effect of the radial gap: $S$ between the impeller side plate and casing at the impeller outlet was investigated. Fig. 11 shows the fluid moment at various gaps, $\mathrm{S}=1,2,5 \mathrm{~mm}$. Absolute values of the fluid moment in $|\Omega / \omega|>0.5$ increase with decreasing the gap. The pressure resistance of the gap becomes larger with decreasing the gap. Therefore, pressure fluctuations become larger 
with the smaller gap, and the fluid force moments increase. However, $\mathbf{M}_{\mathrm{r}}$ in $|\Omega / \omega|<0.5$ is almost independent of the gap. Thus, the gap has almost no effect on the destabilizing character of the precessing backshroud. The effect of this gap: "Gap-A" on the precessing backshroud is different from that of the gap between the impeller outlet and guide vane, generally termed "Gap-B", on the whirling impeller. Fluid forces on the whirling impeller become more destabilizing with the smaller "Gap-B" (Tsujimoto et al. [1988b]).

\section{Rotordynamic Coefficients}

Rotordynamic coefficients were calculated from the measured moments for the convenience of
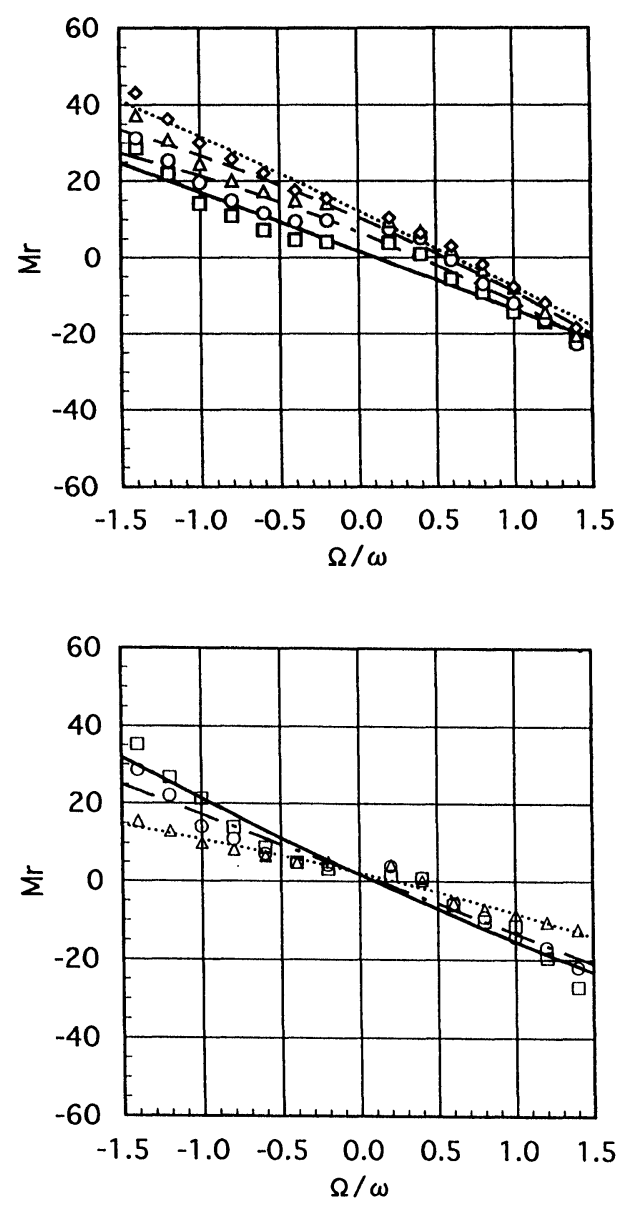

rotordynamic analysis. Using the absolute coordinate system $(\mathrm{x}, \mathrm{y})$ with its origin at the precessing center "O" in Fig. 2, $\mathrm{x}$ - and y-components of the fluid moment, $M_{x}$ and $M_{y}$, are assumed to be represented by the following relation.

$$
\begin{aligned}
{\left[\begin{array}{l}
\mathrm{M}_{\mathrm{x}} \\
\mathrm{M}_{\mathrm{y}}
\end{array}\right]=} & -\left[\begin{array}{rr}
\mathrm{M} & \mathrm{m} \\
-\mathrm{m} & \mathrm{M}
\end{array}\right]\left[\begin{array}{c}
\ddot{\theta}_{\mathrm{x}} \\
\ddot{\theta}_{\mathrm{y}}
\end{array}\right]-\left[\begin{array}{rr}
\mathrm{C} & \mathrm{c} \\
-\mathrm{c} & \mathrm{C}
\end{array}\right]\left[\begin{array}{c}
\dot{\theta}_{\mathrm{x}} \\
\dot{\theta}_{\mathrm{y}}
\end{array}\right] \\
& -\left[\begin{array}{rr}
\mathrm{K} & \mathrm{k} \\
-\mathrm{k} & \mathrm{K}
\end{array}\right]\left[\begin{array}{c}
\theta_{\mathrm{x}} \\
\theta_{\mathrm{y}}
\end{array}\right]
\end{aligned}
$$

where $\mathrm{M}_{\mathrm{x}}, \mathrm{M}_{\mathrm{y}}$ are dimensional values.

In the present study, the geometrical condition around the impeller is symmetric. Therefore, $\mathrm{M}_{\mathrm{r}}$ and $\mathrm{M}_{\mathrm{t}}$ can be expressed by the following quadratic
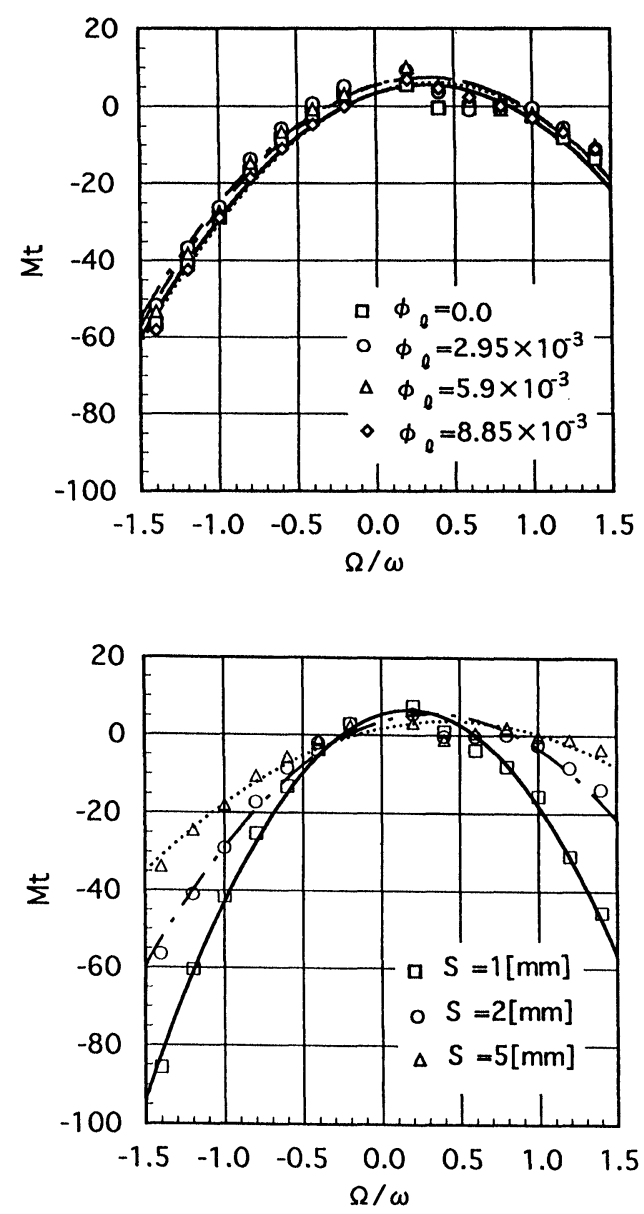

FIGURE 12 Fitted curves of normalized moments (a) influence of leakage flow $\phi_{1}(\phi=0.106, \mathrm{~S}=2 \mathrm{~mm})$ (b) influence of the gap $\mathrm{S}\left(\phi=0.106, \phi_{1}=0.0\right)$. 
TABLE I Rotordynamic coefficients of fluid moment on the backshroud

(a) influence of leakage flow $\phi_{1}(\phi=0.106, \mathrm{~S}=2 \mathrm{~mm})$

\begin{tabular}{|c|c|c|c|c|c|c|}
\hline \multirow{2}{*}{$\frac{\text { Matrix element }}{\text { Normalized by }}$} & M & $\mathrm{m}$ & $\mathrm{C}$ & $\mathrm{c}$ & $\mathrm{K}$ & $\mathrm{k}$ \\
\hline & \multicolumn{2}{|c|}{ I } & \multicolumn{2}{|c|}{$\mathrm{I} \omega$} & \multicolumn{2}{|c|}{$\mathrm{I} \omega^{2}$} \\
\hline$\phi_{l}=0.0$ & -19.6 & -0.04 & -15.3 & -13.0 & -3.20 & -1.82 \\
\hline $2.95 \times 10^{-3}$ & -19.0 & -1.92 & -16.5 & -12.1 & -5.24 & -6.70 \\
\hline $5.90 \times 10^{-3}$ & -19.3 & -1.69 & -17.8 & -12.9 & -5.04 & -10.4 \\
\hline $8.85 \times 10^{-3}$ & -19.5 & -0.25 & -19.7 & -14.5 & -3.13 & -12.3 \\
\hline
\end{tabular}

(b) influence of the gap S $\left(\phi=0.106, \phi_{1}=0.0\right)$

\begin{tabular}{|c|c|c|c|c|c|c|}
\hline \multirow{2}{*}{$\frac{\text { Matrix element }}{\text { Normalized by }}$} & M & \multirow[t]{2}{*}{$\mathrm{m}$} & $\mathrm{C}$ & \multirow[t]{2}{*}{$\mathrm{c}$} & K & $\mathrm{k}$ \\
\hline & I & & $\mathrm{I} \omega$ & & \multicolumn{2}{|c|}{$\mathrm{I} \omega^{2}$} \\
\hline $\mathrm{S}=1 \mathrm{~mm}$ & -35.9 & 1.12 & -18.4 & -12.5 & -5.41 & -1.85 \\
\hline $2 \mathrm{~mm}$ & -19.6 & -0.04 & -15.3 & -13.0 & -3.20 & -1.82 \\
\hline $5 \mathrm{~mm}$ & -10.4 & -0.89 & -9.6 & -9.1 & -1.42 & -2.04 \\
\hline
\end{tabular}

equation using the above matrix elements: rotordynamic coefficients.

$$
\begin{aligned}
& \mathrm{M}_{\mathrm{r}}=\frac{\mathrm{m}}{\mathrm{I}}\left(\frac{\Omega}{\omega}\right)^{2}+\frac{\mathrm{C}}{\mathrm{I} \omega}\left(\frac{\Omega}{\omega}\right)-\frac{\mathrm{k}}{\mathrm{I} \omega^{2}} \\
& \mathrm{M}_{\mathrm{t}}=\frac{\mathrm{M}}{\mathrm{I}}\left(\frac{\Omega}{\omega}\right)^{2}-\frac{\mathrm{c}}{\mathrm{I} \omega}\left(\frac{\Omega}{\omega}\right)-\frac{\mathrm{K}}{\mathrm{I} \omega^{2}}
\end{aligned}
$$

$\mathrm{M}, \mathrm{m}, \mathrm{C}, \mathrm{c}, \mathrm{K}, \mathrm{k}$ are the direct added mass (M), cross-coupled mass $(\mathrm{m})$, direct damping $(\mathrm{C})$, crosscoupled damping (c), direct stiffness $(\mathrm{K})$ and crosscoupled stiffness (k), respectively. Figure 12 shows the quadratic curve fittings to calculate the rotordynamic coefficients from the measured nondimensional moments. $\mathrm{M}_{\mathrm{t}}$ can be fitted fairly well by a quadratic curve, however $\mathrm{M}_{\mathrm{r}}$ can't be fitted well, in particularly at small positive precessing frequency. Table I shows the calculated rotordynamic coefficients of fluid force moments on the backshroud.

Cross-coupled stiffness (k), which plays an important role for the stability, decreases with increasing the leakage flow, but direct added mass (M) is independent of the leakage flow. On the other hand, direct added mass (M) decreases with decreasing the gap $\mathrm{S}$, however cross-coupled stiffness (k) is independent of the gap.

\section{CONCLUSIONS}

Fluid force moments on the backshroud of the precessing centrifugal impeller were studied from the detailed flow measurements. The effects of the leakage flow in the backshroud/casing clearance and the gap between impeller side plate and casing at the impeller outlet were investigated.

Pressure patterns rotating with the precessing frequency, which generate the fluid force moments, were clearly shown. The pressure field depends on the precessing/rotating speed ratio: $\Omega / \omega$, therefore the fluid force moments $\left(M_{r}, M_{t}\right)$ are dependent on $\Omega / \omega$. In general, $\mathbf{M}_{\mathrm{r}}$ is positive at small forward precessing frequency: $0<\Omega / \omega<0.5$, that is rotordynamically destabilizing on the precessing motion. In addition to this, it is found that;

- The fluid force moments are almost independent of the pump flow rate.

- The fluid force moments become more destabilizing with increasing the leakage flow.

- The absolute values of the fluid force moments become larger with decreasing the gap ("Gap-A") at the impeller outlet.

- The swirl in the backshroud/casing clearance increases with increasing the leakage flow, which has the effect on the cross-coupling stiffness $(\mathrm{k})$ 
of the rotordynamic coefficients. The pressure resistance at the impeller outlet increases with decreasing the gap, which has the effect on the direct mass $(\mathrm{M})$ of the rotordynamic coefficients.

\section{Acknowledgment}

The authors would like to acknowledge the much effort of Mr. Teramoto in support of this program as a graduate project at Osaka University. Present study was partly supported by the Ministry of Education, Science, Sports and Culture through the Grant-in-Aid for Developmental Scientific Research B (No. 06555055).

\section{NOMENCLATURE}

$b_{2} \quad$ impeller outlet height

$\mathrm{C}, \mathrm{c}$ direct damping, cross-coupled damping

$\mathrm{C}_{\mathrm{p}} \quad$ pressure coefficient $\left(=\left(\mathrm{P}-\mathrm{P}_{1 \mathrm{t}}\right) / \rho\left(\mathrm{r}_{2} \omega\right)^{2}\right)$

$\mathrm{H}$ backshroud/casing clearance

$\mathrm{H}_{\mathrm{o}} \quad$ mean backshroud/casing clearance

$\mathrm{K}, \mathrm{k}$ direct stiffness, cross-coupled stiffness

M, m direct added mass, cross-coupled mass

$\mathrm{M}_{\mathrm{r}} \quad$ radial component of fluid force moment (normalized by $\mathrm{M}_{\mathrm{o}}$ )

$\mathrm{M}_{\mathrm{t}} \quad$ tangential component of fluid force moment (normalized by $\mathrm{M}_{\mathrm{o}}$ )

$\mathrm{M}_{\mathrm{o}}=\mathrm{I} \alpha \omega^{2}, \mathrm{I}=\rho \pi \mathrm{r}_{2}^{2} \mathrm{~b}_{2} \mathrm{i}^{2}, \mathrm{i}=\sqrt{\mathrm{r}_{2}^{2} / 4+\mathrm{b}_{2}^{2} / 12}$

$\mathrm{P}, \mathrm{p}$ pressure (steady, unsteady component)

$\mathrm{r}$ radius

$\mathrm{r}_{2} \quad$ impeller outer radius

$\mathrm{S} \quad$ gap between impeller side plate and casing ("Gap-A")

$\mathrm{U}_{\mathrm{r}} \quad$ radial velocity (positive outerward)

$\mathrm{U}_{\theta} \quad$ circumferential velocity (positive in the direction of impeller rotion)

\section{Greek Letters}

$\alpha$ inclination of the shaft

$\rho \quad$ fluid density

$\phi \quad$ flow coefficient $\left(=\mathrm{Q} / 2 \pi \mathrm{r}_{2}^{2} \omega \mathrm{b}_{2}, \mathrm{Q}\right.$ : pump flow rate) $\phi_{1}$ leakage flow coefficient $\left(=\mathrm{Q}_{1} / 2 \pi \mathrm{r}_{2}^{2} \omega \mathrm{b}_{2}\right.$, $\mathrm{Q}_{1}$ : leakage flow rate)

$\omega$ precessing speed $[\mathrm{rad} / \mathrm{sec}]$

$\Omega$ pump rotation speed $[\mathrm{rad} / \mathrm{sec}]$

$\psi \quad$ static pressure coefficient $\left(=\left(\mathrm{P}_{2}-\mathrm{P}_{1 \mathrm{t}}\right) /\right.$ $\left.\rho\left(\mathrm{r}_{2} \omega\right)^{2}\right)$

\section{References}

Adkin, D.R. and Brennen, C.E., 1988. "Analyses of Hydraulic Radial Forces on Centrifugal Pump Impellers", $A S M E$ Journal of Fluids Engineering, Vol. 110, pp. 20-28.

Baskharone, E.A., Daniel, A.S. and Hensel, S.J., 1994 "Rotordynamic Effects of the Shroud-to-Housing Leakage Flow in Centrifugal Pumps", ASME Journal of Fluids Engineering, Vol. 116, pp. 558-563.

Bolleter, U., Wyss, A., Welte, I. and Sturcher, R., 1987. "Measurement of Hydrodynamic Interaction Matrices of Boiler Feed Pump Impeller", ASME Journal of Vibration, Acoustics, Stress and Reliability in Design, Vol. 109, pp. 144151

Chamieh, D.S., Acosta, A.J., Brennen, C.E. and Caughey, T.K. 1985. "Experimental Measurements of Hydrodynamic Radial Forces and Stiffness Matrices for Centrifugal PumpImpeller", ASME Journal of Fluids Engineering, Vol. 107, pp. 307-315.

Childs, D.W., 1989. "Fluid Structure International Forces at Pump-Impeller-Shroud Surfaces for Rotordynamics Calculation”, ASME Journal of Vibration, Acoustics, Stress and Reliability in Design, Vol. 111, pp. 216-225.

Guelich, J., Florjancic, D. and Pace, S.E., 1989. "Influence of Flow Between Impeller and Casing on Part-Load Performance of Centrifugal Pumps", ASME FED-81, pp. 227-235.

Guinzburg, A., Brennen, C.E., Acosta, A.J. and Caughey, T. K. 1993. "The effect of Inlet Swirl on the Rotordynamic Shroud Forces in Centrifugal Pump", ASME Journal of Engineering for Gas Turbine and Power, Vol. 115, pp. 287-293.

Ohashi, H. and Shoji, H., 1984. "Lateral Fluid Forces Acting on a Whirling Centrifugal Impeller in Vaneless and Vaned Diffuser”, NASA Conf. Pub. 2338, pp. 109-122.

Ohashi, H., Sakurai, A. and Nishihama, J., 1988. "Influence of Impeller and Diffuser Geometries on the Lateral Fluid Forces of Whirling Centrifugal Impeller", NASA Conf. Pub. 3026, pp. 285-306.

Ohashi, H., Imai, H. and Tsuchihashi, T., 1991. "Fluid Force and Moment on Centrifugal Impellers in Precession Motion", ASME Fluid Machinery Forum, FED-Vol. 119, pp. 57-60.

Shoji, H. and Ohashi, H., 1987. "Lateral Fluid Forces on Whirling Centrifugal Impeller", ASME Journal of Fluids Engineering, Vol. 109, pp. 94-99.

Tsujimoto, Y., Acosta, A.J. and Brennen, C.E., 1988a "Theoretical Study of Fluid Forces on a Centrifugal Impeller Rotating and Whirling in a Volute", ASME Journal of Vibration, Acoustics, Stress and Reliability in Design, Vol. 110 , pp. 263-269.

Tsujimoto, Y., Acosta, A. and Yoshida, Y., 1988b. "A Theoretical Study of Fluid Forces on a Centrifügal Impelle Rotating and Whirling in a Vaned Diffuser", NASA Conf. Pub. 3026, pp. 307-322. 


\section{ait \\ ENERGY MATERIALS}

M A N E Y publishing

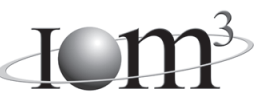

\section{Materials Science \& Engineering for Energy Systems}

Maney Publishing on behalf of the Institute of Materials, Minerals and Mining

The Institute of Materials, Minerals \& Mining

Economic and environmental factors are creating ever greater pressures for the efficient generation, transmission and use of energy. Materials developments are crucial to progress in all these areas: to innovation in design; to extending lifetime and maintenance intervals; and to successful operation in more demanding environments. Drawing together the broad community with interests in these areas, Energy Materials addresses materials needs in future energy generation, transmission, utilisation, conservation and storage. The journal covers thermal generation and gas turbines; renewable power (wind, wave, tidal, hydro, solar and geothermal); fuel cells (low and high temperature); materials issues relevant to biomass and biotechnology; nuclear power generation (fission and fusion); hydrogen generation and storage in the context of the 'hydrogen economy'; and the transmission and storage of the energy produced.

As well as publishing high-quality peer-reviewed research, Energy Materials promotes discussion of issues common to all sectors, through commissioned reviews and commentaries. The journal includes coverage of energy economics and policy, and broader social issues, since the political and legislative context influence research and investment decisions.

\section{CALL FOR PAPERS}

Contributions to the journal should be submitted online at http://ema.edmgr.com

To view the Notes for Contributors please visit: www.maney.co.uk/journals/notes/ema

Upon publication in 2006, this journal will be available via the Ingenta Connect journals service. To view free sample content online visit: www.ingentaconnect.com/content/maney

For further information please contact:

Maney Publishing UK

Tel: +44 (0)113 2497481 Fax: +44 (0)1132486983 Email: subscriptions@maney.co.uk

or

Maney Publishing North America

Tel (toll free): 8662975154 Fax: 6173546875 Email: maney@maneyusa.com

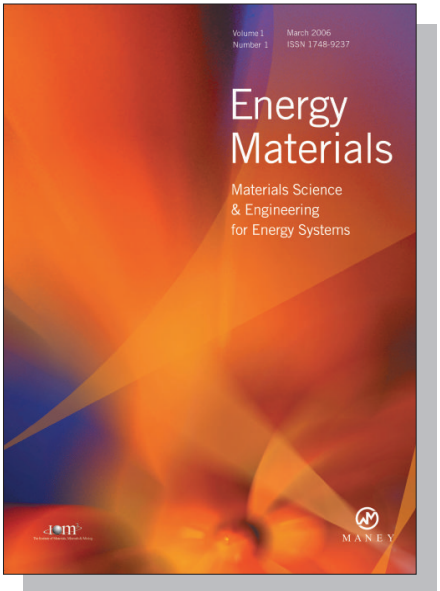

EDITORS

Dr Fujio Abe

NIMS, Japan

Dr John Hald, IPL-MPT, Technical University of Denmark, Denmark

Dr R Viswanathan, EPRI, USA

\section{SUBSCRIPTION INFORMATION}

Volume 1 (2006), 4 issues per year

Print ISSN: 1748-9237 Online ISSN: 1748-9245

Individual rate: $£ 76.00 / U S \$ 141.00$

Institutional rate: $£ 235.00 /$ US $\$ 435.00$

Online-only institutional rate: $£ 199.00 / U S \$ 367.00$

For special $\mathrm{IOM}^{3}$ member rates please email

subscriptions@maney.co.uk

\section{For further information or to subscribe online please visit www.maney.co.uk}



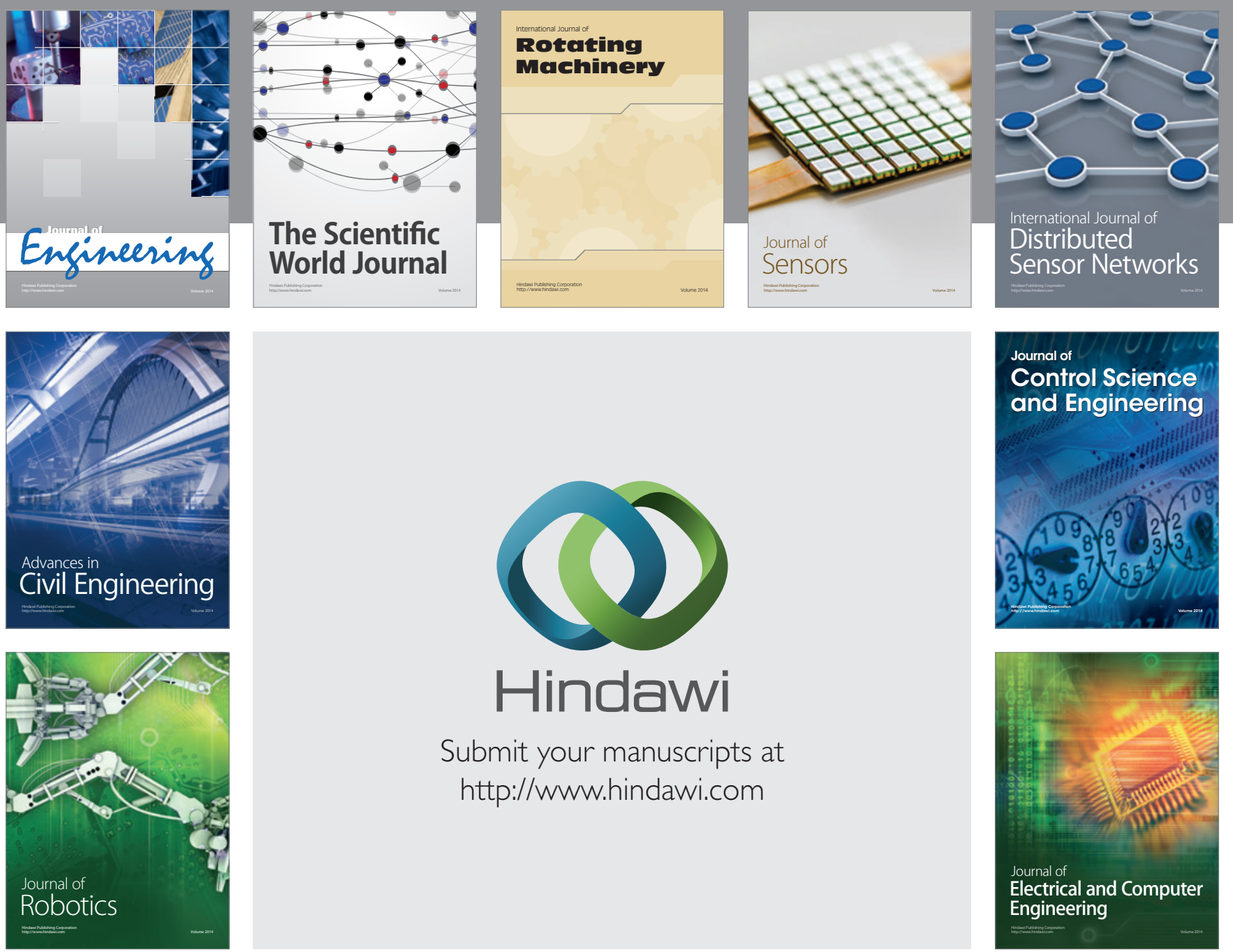

Submit your manuscripts at

http://www.hindawi.com
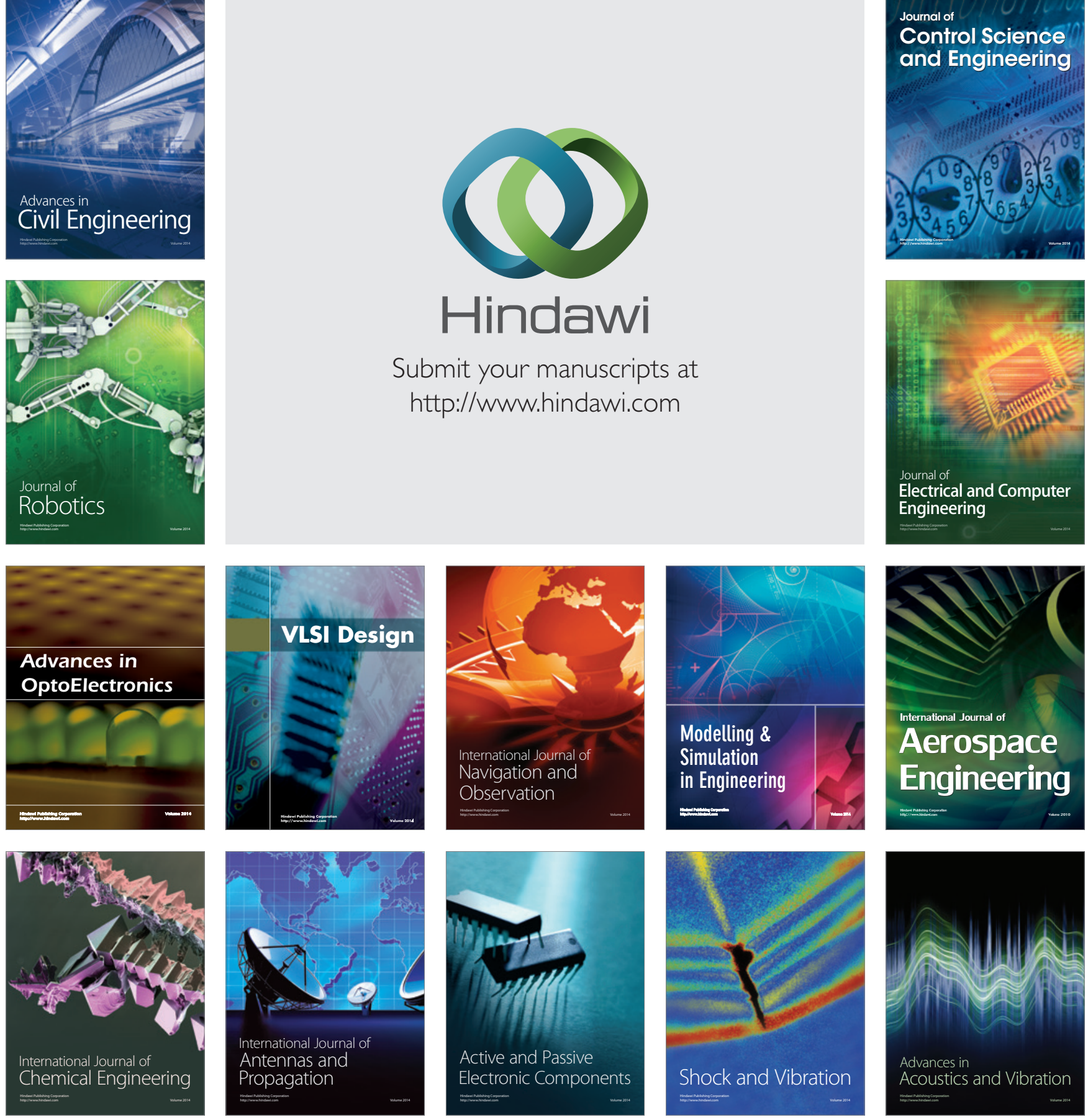